Article

\title{
Liquid Chromatography with a Fluorimetric Detection Method for Analysis of Paralytic Shellfish Toxins and Tetrodotoxin Based on a Porous Graphitic Carbon Column
}

\author{
Veronica Rey ${ }^{1}$, Ana M. Botana ${ }^{1, *}$, Mercedes Alvarez ${ }^{2}$, Alvaro Antelo ${ }^{2}$ and Luis M. Botana ${ }^{3, *}$ \\ 1 Department Analytical Chemistry, Faculty of Sciences, University of Santiago de Compostela, Lugo 27002, \\ Spain; veronica.rey@rai.usc.es \\ 2 CIFGA S.A., Plaza Santo Domingo 20-5a , Lugo 27001, Spain; mercedes@cifga.es (M.A.); \\ alvaro@cifga.es (A.A.) \\ 3 Department Pharmacology, Veterinary Faculty, University of Santiago de Compostela, Lugo 27002, Spain \\ * Correspondence: anamaria.botana@usc.es (A.M.B.); luis.botana@usc.es (L.M.B.); \\ Tel.: +34-982-824-071 (A.M.B.); +34-982-822-233 (L.M.B.)
}

Academic Editor: Jose M. Eirin-Lopez

Received: 16 May 2016; Accepted: 23 June 2016; Published: 28 June 2016

\begin{abstract}
Paralytic shellfish toxins (PST) traditionally have been analyzed by liquid chromatography with either pre- or post-column derivatization and always with a silica-based stationary phase. This technique resulted in different methods that need more than one run to analyze the toxins. Furthermore, tetrodotoxin (TTX) was recently found in bivalves of northward locations in Europe due to climate change, so it is important to analyze it along with PST because their signs of toxicity are similar in the bioassay. The methods described here detail a new approach to eliminate different runs, by using a new porous graphitic carbon stationary phase. Firstly we describe the separation of 13 PST that belong to different groups, taking into account the side-chains of substituents, in one single run of less than $30 \mathrm{~min}$ with good reproducibility. The method was assayed in four shellfish matrices: mussel (Mytillus galloprovincialis), clam (Pecten maximus), scallop (Ruditapes decussatus) and oyster (Ostrea edulis). The results for all of the parameters studied are provided, and the detection limits for the majority of toxins were improved with regard to previous liquid chromatography methods: the lowest values were those for decarbamoyl-gonyautoxin 2 (dcGTX2) and gonyautoxin 2 (GTX2) in

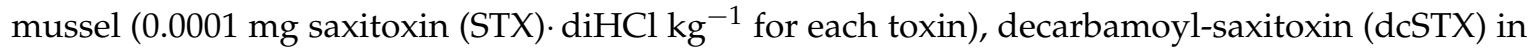
clam (0.0003 mg STX. diHCl kg $\left.{ }^{-1}\right), N$-sulfocarbamoyl-gonyautoxins 2 and 3 (C1 and C2) in scallop (0.0001 mg STX. diHCl kg-1 for each toxin) and dcSTX $\left(0.0003 \mathrm{mg} \mathrm{STX} \cdot \mathrm{diHCl} \mathrm{kg}{ }^{-1}\right)$ in oyster; gonyautoxin 2 (GTX2) showed the highest limit of detection in oyster $\left(0.0366 \mathrm{mg} \mathrm{STX} \cdot \mathrm{diHCl} \mathrm{kg}^{-1}\right)$. Secondly, we propose a modification of the method for the simultaneous analysis of PST and TTX, with some minor changes in the solvent gradient, although the detection limit for TTX does not allow its use nowadays for regulatory purposes.
\end{abstract}

Keywords: paralytic shellfish toxins; tetrodotoxin; porous graphitic carbon; post-column oxidation liquid chromatography; shellfish matrices

\section{Introduction}

Marine biotoxins are produced by more than 200 marine algal species. They are complex secondary metabolite molecules with high toxicity and an unknown physiological role. The intake of these compounds can lead to serious toxic effects in humans, including death [1,2]. 
Paralytic shellfish toxins (PST) cause persistent problems in humans due to their accumulation in filter feeding shellfish [3], but they can also move up through the food chain, affecting zooplankton, fish, birds and marine mammals [4]. PST intoxications are a result of exposure to saxitoxins (STXs), gonyautoxins (GTXs) and N-sulfocarbamoyl-gonyautoxins (Cs). More than 57 different analogues of saxitoxin (STX) have been described to date [5,6].

Analytical methods can be used to detect and quantify PST. High performance liquid chromatography (HPLC) was one of the first analytical methods developed for STX detection, and it is routinely used. The basis of the HPLC method for PST analysis was established in the late 1970s, using post-column derivatization with a silica-based stationary phase [7]. Since then, many methods for toxin separation have been developed using both pre- and post-column oxidation with different types of columns. A variety of modifications have led to improved separation and detection of the different congeners, including sample extraction, type of column, eluent composition and oxidation processes [8]. The most common chemical method uses a combination of HPLC with either pre- or post-column oxidation followed by fluorescence detection (FLD) [9,10]. The Lawrence method has been validated by the Association of Official Analytical Chemists (AOAC) through a collaborative trial [11] and was adopted as the First Action HPLC-FLD Official Method [12]. It involves separation of the PST after their derivatization and further fluorescence detection. The original method was refined and extended to include other toxins in mussel and other matrices [13-15]. The major challenge of the pre-column oxidation method is that the chromatographic separation is performed on the oxidized reaction products. Many of the toxins have reaction products with more than one peak, namely, decarbamoyl-GTX2,3 (dcGTX2,3), neosaxitoxin (NEO), GTX6, GTX1,4, C3,4, dcSTX and dcNEO, and some of them coelute after the periodate oxidation. This happens for the two peaks of both dcSTX and dcNEO, the second peak of GTX1,4 (with three peaks) and of dcGTX2,3, the third one of GTX1,4 and the single peak of GTX2,3. Therefore, a misidentification and wrong quantification of several PST could take place [16]. Moreover, this method is unable to separate pairs of isomers; hence, the total toxicity of the samples is overestimated by using the highest toxicity equivalency factor (TEF) [17-19] for those isomers that yield the same coeluting oxidation products.

The post-column technique published by Oshima [20] was modified by Thomas et al. [10] and then further refined by Rourke et al. [21]. These modifications included different clean-up procedures, eluent composition, HPLC columns and oxidation conditions. Nevertheless, it is necessary to perform two analyses with two different columns to identify and quantify the whole variety of PSTs.

The post-column oxidation (PCOX) method has undergone a single laboratory validation [22] and a collaborative validation [23], and it was adopted as an official AOAC method [24]. The advantage of this method is that it enables quantification and isolation of each epimer individually and shows a good correlation with the mouse bioassay; on the contrary it requires additional time to change columns, and the column lifetime is shortened due to the use of ion pairing reagents in mobile phases; it also shows interferences of naturally fluorescent compounds present in matrices, as Biré et al. [25] remarked. Furthermore, Boundy et al. [26] have recently developed a hydrophilic interaction ultra-performance liquid chromatography tandem mass spectrometry (HILIC UPLC-MS/MS) method for PST that includes an optimized desalting clean-up procedure using carbon solid phase extraction cartridges to reduce matrix interferences.

In addition to all of the above, tetrodotoxin (TTX), has been reported in Greek and English bivalves [27,28], and it has the same toxicity symptoms and mechanism of action as PST [29]. TTX is a potent neurotoxin with a low molecular weight, is water soluble and heat stable; therefore cooking does not reduce its toxicity, but it may increase its toxic effect [30]. It frequently causes intoxications due to the ingestion of puffer fish, very common in Japan [31]. Although TTX exists mainly in tropical waters around the world, recent studies have demonstrated that it has appeared on the European coasts and up to England, due to climate change [28]. This is possibly due to "Lessepsian migration": the opening of the Suez Canal caused the migration of many Red Sea species to colonize the Mediterranean Sea [32]. 
After a serious intoxication with TTX by ingestion of gastropods [33], it was clear that TTX was a food safety concern in Europe. Furthermore, the co-occurrence of TTX with PST has been reported in many species of puffer fish, crabs and gastropods [34]. Currently, there is no official method for detecting these toxins; however, the mouse bioassay has been used in many cases to determine their toxicity [35]. Since they block sodium channels in a similar fashion as STX [36], their presence in seafood would be misdiagnosed by the mouse bioassay [29]. To obtain specific information from a sample, such as the toxin profile or the amount of a single analogue, chemical methods have been developed based on HPLC-FLD [37]. Although these methods ensure low detection limits, liquid-chromatography-mass spectrometry (LC-MS) and especially LC-MS/MS [29] are generally regarded as the best choice for the determination of TTX and related compounds.

Regulatory limits have not been established for this toxin and its analogues [38]. The European Food Safety Authority (EFSA) has not published any document regarding risks from TTX, but some authors affirm that the minimum toxic dose in humans is $2 \mathrm{mg}$ [31,39].

This work proposes a new method to determine simultaneously all PST with a porous graphitic carbon column using HPLC-FLD. The method proposes also a modification for the separation of PST alongside TTX. We proved that it was possible to analyze all of these toxins together and in a short time, compared to other chromatographic methods.

\section{Results and Discussion}

\subsection{Chromatographic Conditions}

Although the initial chromatographic conditions for PCOX separation of PSTs were those reported by Van de Riet et al. [22], several modifications were accomplished: the column and mobile phase were different. While in PCOX the separation is based on the use of heptane sulfonate and tetrabutyl ammonium phosphate, in this case, the mobile phase was based on the use of trifluoroacetic acid (TFA). The post-column conditions were kept with slight modifications: the oxidant was the same, but the flow rate was different $\left(0.4 \mathrm{~mL} \cdot \mathrm{min}^{-1}\right.$ in PCOX and $0.5 \mathrm{~mL} \cdot \mathrm{min}^{-1}$ in this work); the concentration of nitric acid was also changed, from $0.75 \mathrm{M}$ at a flow rate of $0.4 \mathrm{~mL} \cdot \mathrm{min}^{-1}$ to $0.1 \mathrm{M}$ at a flow rate of $0.3 \mathrm{~mL} \cdot \mathrm{min}^{-1}$. These modifications in acid concentration and flow rate and in the oxidant flow rate were performed to achieve a final outflow $\mathrm{pH}$ in the range between five and seven [17]. Several parameters were tested to obtain the best sensitivity and resolution. The initial conditions were: $0.025 \%$ TFA in Solvents A and $\mathrm{B}$, column temperature $15^{\circ} \mathrm{C}$, reaction temperature $80^{\circ} \mathrm{C}$ and outflow $\mathrm{pH}=6$.

\subsubsection{Development of TFA as an Ion Pairing Agent}

Once the appropriate gradient for separating all toxins was achieved, the percentage of TFA was then tested. TFA can act as a competitive electronic modifier in the mobile phase to change the polar retention. It forms an ion pair with the analyte, increasing retention times for most of the toxins when its concentration was increased: dcNEO was delayed 1-1.5 min; dcSTX, dcGTX2, dcGTX3, STX, NEO and GTX5 were delayed 3-3.5 min; GTX2, GTX3, GTX1 and GTX4 were delayed $1 \mathrm{~min}$; C1 and C2 were advanced $0.5-1$ min (Figure 1). On the other hand, the resolution and peak shape were also improved through electronic interactions with the graphite surface. The porous graphite column stability allows high concentrations of aggressive buffers, such as 1\% TFA, to be used with no detrimental effect on the column lifetime, but when the concentration of TFA is increased beyond $0.1 \%$, there is a significant effect on the peak shape and resolution of the basic analytes, according to manufacturer indications [40]. Therefore, different percentages of TFA in the mobile phase for both Solvents A and B were assayed: specifically, $0.025 \%, 0.050 \%$ and $0.075 \%$, while column temperature, reaction temperature and outflow $\mathrm{pH}$ remained at their initial conditions $\left(15^{\circ} \mathrm{C}, 80^{\circ} \mathrm{C}\right.$ and six, respectively).

At this stage, the interpretation of the quality of separation was based on the resolution between adjoining peaks and their symmetry. A concentration of $0.025 \%$ TFA was ideal for the separation of the last eluting toxins, although this low percentage of TFA decreased the peak resolution of 
earlier eluted toxins (dcNEO, dcSTX, NEO, STX and dcGTX3), as well as the symmetry and number of theoretical plates; therefore, higher amounts of TFA $(0.075 \%)$ were necessary to improve these parameters. According to this, different combinations of concentrations for Solvents A and B were tried, and the best performing mixture was $0.075 \%$ TFA in Solvent A and 0.025\% TFA in Solvent $\mathrm{B}$; these results are shown in Figure 1 (in this figure, the optimized analysis time is not shown). The improvement in the separation obtained with TFA for the di-cationic PST (dcNEO, dcSTX, STX and NEO) seemed to be related to the role that TFA plays as an ion-pair reagent and not only to the acidification of the medium. Therefore, the TFA percentage was an important issue to take into account.

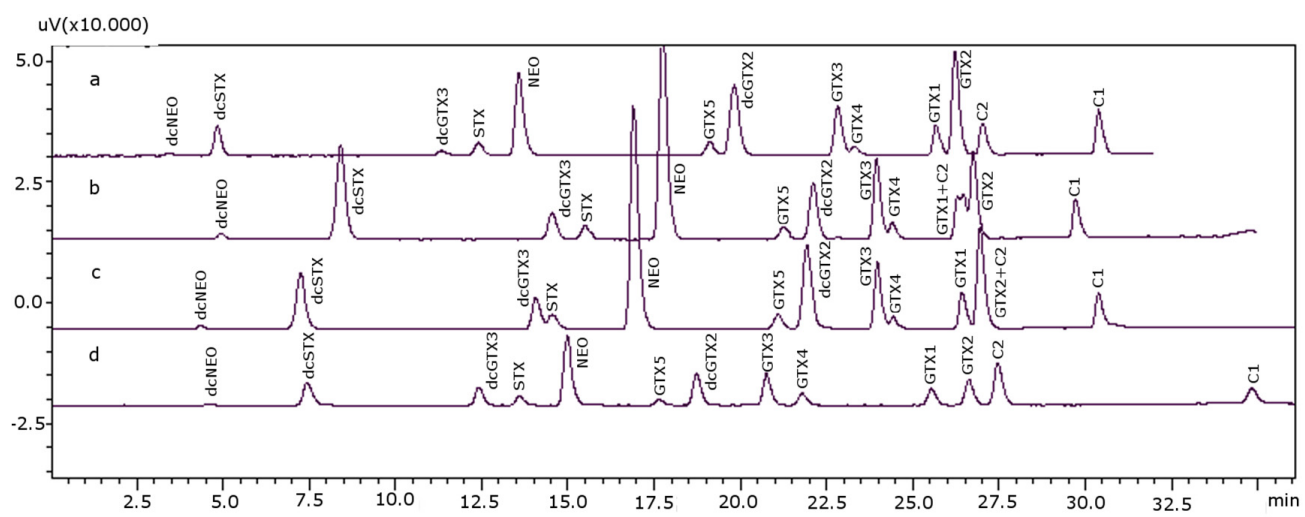

Figure 1. Chromatographic separation of paralytic shellfish toxins (PST) standards using different percentages of trifluoroacetic acid (TFA) in the mobile phase (the analysis time is not optimized for all of the parameters of the method): (a) 0.025\% TFA in Solvents A and B; (b) 0.05\% TFA in Solvents A and B; (c) $0.075 \%$ TFA in Solvents A and B; (d) $0.075 \%$ TFA in Solvent A and 0.025\% in Solvent B. Concentrations used for the standards (as mg saxitoxin (STX) $\cdot \mathrm{diHCl} \mathrm{eq} \cdot \mathrm{kg}^{-1}$ ): 0.1387 for decarbamoyl-neosaxitoxin (dcNEO), 0.1337 for dcSTX, 0.0018 for dc gonyautoxin 3 (dcGTX3), 0.4182 for STX, 0.6761 for NEO, 0.0020 for GTX5, 0.0045 for dcGTX2, 0.0523 for GTX3, 0.0016 for GTX4, 0.0080 for GTX1, 0.0419 for GTX2, 0.0002 for C1 and 0.0012 for C2.

\subsubsection{Detector Outflow pH}

Once the optimal mobile phase composition was accomplished, the effect of $\mathrm{pH}$ on the oxidation of PST was studied to establish the conditions that produced the maximum fluorescence in the oxidized products (column and reaction temperature remained the same). Vale et al. [17] suggested that the outflow $\mathrm{pH}$ should be in the range between five and seven; in order to get a value in this range, several combinations of oxidant and acid flow rates were tested, and the working outflow pHs were 5, 6 and 7. The best resolution was obtained at $\mathrm{pH}=5$. To carry out these tests, both column temperature and reaction temperature were not modified, and \%TFA was $0.075 \%$ in Solvent A and $0.025 \%$ in B, as was described in the previous section. These conditions allowed a good separation in an acceptable run time.

\subsubsection{Reaction Temperature}

The reaction temperature was optimized while column temperature remained at $15^{\circ} \mathrm{C}$, its initial value; this working temperature depends on the type of heat source, water bath or reactor [20]. As the equipment setup was attached to an online water bath, the following temperatures were assayed: $65^{\circ} \mathrm{C}$, $70^{\circ} \mathrm{C}, 75^{\circ} \mathrm{C}, 80^{\circ} \mathrm{C}$ and $85^{\circ} \mathrm{C}$. The temperature that produced the peaks with the highest signal:noise ratio was $75^{\circ} \mathrm{C}$. Figure 2 shows the chromatograms at some of those temperatures: dcNEO, dcSTX, dcGTX3, GTX5 and GTX4 peaks are bigger at $75^{\circ} \mathrm{C}$ than at other temperatures; this is quite important in the case of dcNEO due to its low signal and also for dcGTX3, GTX5 and GTX4. Comparison of peaks at $65{ }^{\circ} \mathrm{C}$ and the optimal temperature $75^{\circ} \mathrm{C}$ gave the following: dcNEO, dcGTX3 and GTX4 were $40 \%$ higher at $75^{\circ} \mathrm{C}$ than at $65{ }^{\circ} \mathrm{C}$; dcSTX and GTX5 were $50 \%$ higher at the optimal temperature than at $65{ }^{\circ} \mathrm{C}$. The rest of the peaks increased their height between $15 \%$ and $30 \%$. 


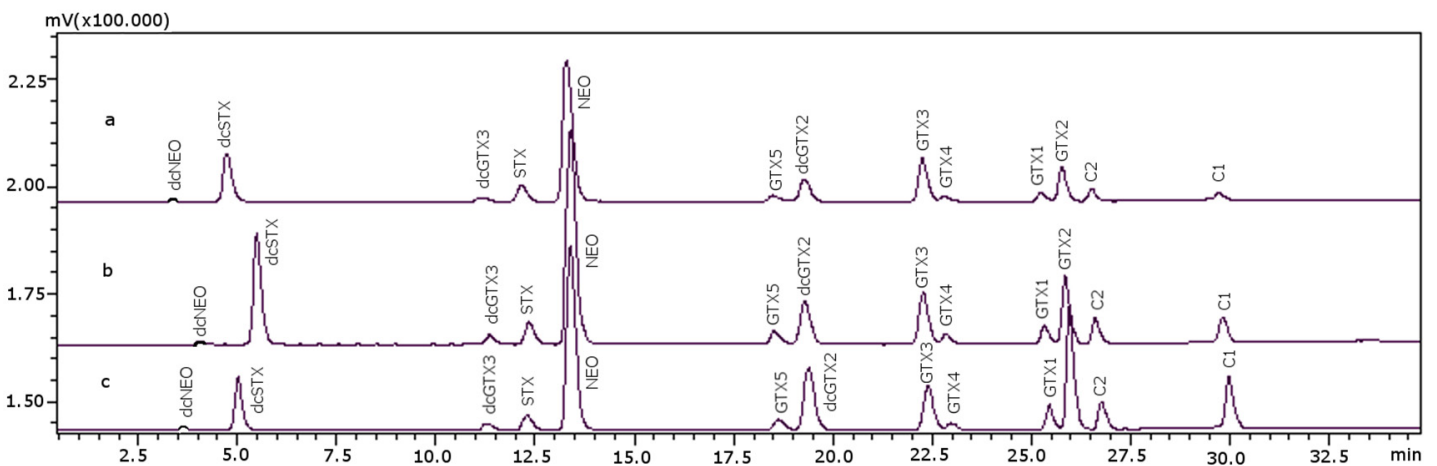

Figure 2. Chromatograms of PST standards obtained at different reaction temperatures (the analysis time is not optimized for all of the parameters of the method): (a) $65{ }^{\circ} \mathrm{C}$; (b) $75{ }^{\circ} \mathrm{C}$; (c) $85^{\circ} \mathrm{C}$. Concentrations used for the standards (as mg STX. diHCl eq. $\mathrm{kg}^{-1}$ ): 0.1387 for dcNEO, 0.1337 for dcSTX, 0.0018 for dcGTX3, 0.4182 for STX, 0.6761 for NEO, 0.0020 for GTX5, 0.0045 for dcGTX2, 0.0523 for GTX3, 0.0016 for GTX4, 0.0080 for GTX1, 0.0419 for GTX2, 0.0002 for C1 and 0.0012 for C2.

\subsubsection{Column Temperature}

Column temperature was the last parameter to be optimized. In this method, $\mathrm{C} 1$ and $\mathrm{C} 2$ toxins and GTXs and STXs groups were analyzed in one single run, whereas the PCOX method [22] required two columns for the same purpose, one for $\mathrm{Cs}$ with temperature below room conditions to prevent on-column epimerization of $\mathrm{C} 1$ and $\mathrm{C} 2$ and another one for the rest of the toxins. Therefore, the optimal column temperature was investigated for all of the toxins in a range from $15{ }^{\circ} \mathrm{C}$ (minimal oven temperature) and up to $35^{\circ} \mathrm{C}$. At $20^{\circ} \mathrm{C}$, the peak signals showed the highest values: for temperatures above $20^{\circ} \mathrm{C}$, the peaks size decreased, and the retention times decreased, resulting in the overlapping of both dcSTX and dcNEO, between them and with the solvent front. Therefore, $20^{\circ} \mathrm{C}$ was established as the best temperature, and the optimized separation is shown in Figure 3.

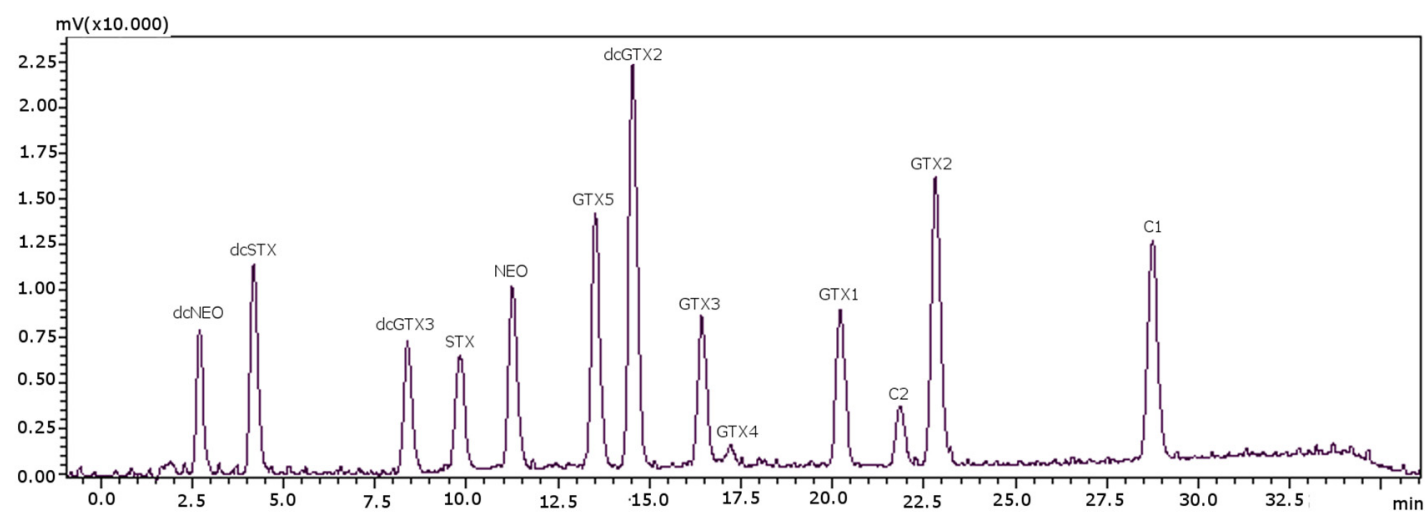

Figure 3. Chromatographic separation of PST standards with the post-column oxidation method, using a porous graphitic carbon column. Concentrations used for the standards (as mg STX $\cdot \mathrm{diHCl} \mathrm{eq} \cdot \mathrm{kg}^{-1}$ ): 0.6780 for dcNEO, 0.4354 for dcSTX, 0.0793 for dcGTX3, 1.0634 for STX, 1.6910 for NEO, 0.0956 for GTX5, 0.1062 for dcGTX2, 0.2107 for GTX3, 0.0160 for GTX4, 0.0858 for GTX1, 0.1656 for GTX2, 0.0021 for $\mathrm{C} 1$ and 0.0248 for $\mathrm{C} 2$.

\subsection{Extraction and Sample Clean-Up}

The aim of this work was to establish the validation parameters of the method for the column; therefore, the samples used must not be contaminated with either PST or TTX. A contaminated scallop sample is shown in Figure 4, as an example of the separation of PST with this column for the optimized conditions. 


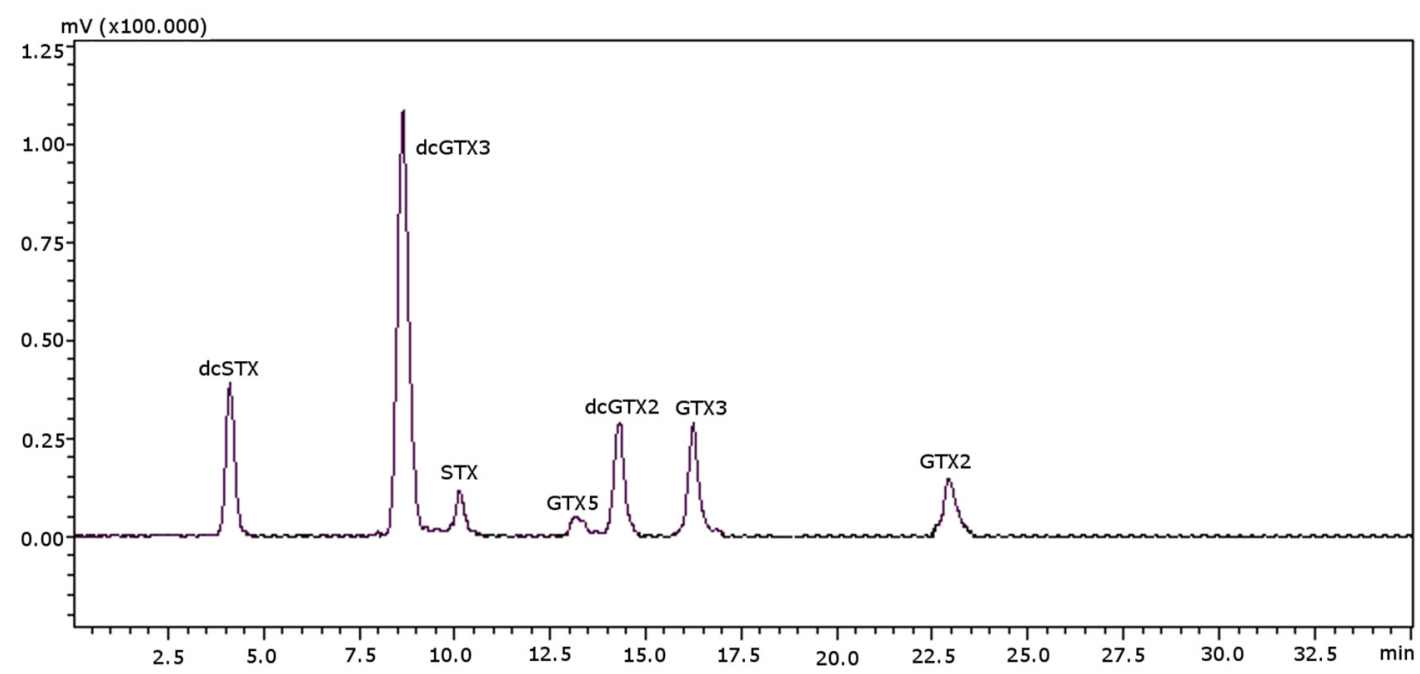

Figure 4. Chromatographic separation of PST in a real scallop sample using a porous graphitic carbon column. Concentrations used for the standards (as $\mathrm{mg} \mathrm{STX} \cdot \mathrm{diHCl}$ eq $\cdot \mathrm{kg}^{-1}$ ): 0.2857 for dcSTX, 0.3217 for dcGTX3, 1.6801 for STX, 0.0406 for GTX5, 0.0476 for dcGTX2, 0.0401 for GTX3, 0.3280 for GTX2.

PSTs were extracted using the AOAC mouse bioassay (MBA) method [41]. Many authors [42-44] have suggested that the MBA extraction with $\mathrm{HCl} 0.1 \mathrm{M}$ is useful in monitoring programs, because it detects the composite toxicity in samples, while the acetic acid extraction (Lawrence method) is more suitable for studying the toxin profile in samples. The main disadvantage of $\mathrm{HCl}$ extraction $[42,43]$ is that $\mathrm{N}$-sulfocarbamoyl toxins are easily converted under mild acid treatment and heat into their corresponding carbamate toxins. Acetic acid extracts have a $\mathrm{pH}$ between 4 and 4.5 , while the $\mathrm{pH}$ of the hydrochloric extracts is three; the recovery of these extracts at $\mathrm{pH}=3$ during SPE-C18 clean-up increases the toxicity in the $\mathrm{HCl}$ extraction $[17,21,45]$. In order to maintain the essence of the PCOX extraction, the hydrochloric extraction procedure was chosen in this work.

\subsection{Validation Parameters}

Table 1 shows the linearity results for each individual paralytic shellfish toxin. All of the correlation coefficients were higher than 0.99 (except one with 0.985). Peak areas were linear between the following lowest and highest concentration values: $0.117-16.003 \mathrm{mg} \mathrm{STX} \cdot \mathrm{diHCl} \mathrm{eq} \cdot \mathrm{kg}^{-1}$, respectively, for all toxins. The range of linearity obtained was not as broad as in the PCOX method; nevertheless, the regulatory limit of $0.8 \mathrm{mg} \mathrm{STX} \cdot \mathrm{diHCl} \mathrm{eq} \cdot \mathrm{kg}^{-1}$ is well within this range.

Table 2 shows limit of detection (LOD) values for PSTs in mussel, clam, scallop and oyster. These values ranged from 0.0001 to $0.0366 \mathrm{mg} \mathrm{STX} \cdot \mathrm{diHCl} \mathrm{eq} \cdot \mathrm{kg}^{-1}$. The lowest values were those for dcGTX2 and GTX2 in mussel and C1 and C2 in scallop; GTX2 showed the highest LOD in oyster, being $0.0366 \mathrm{mg}$ STX. diHCl eq. $\mathrm{kg}^{-1}$. These results were better than those obtained for the PCOX method in our laboratory [46], where LODs ranged from $0.0001 \mathrm{mg} \mathrm{STX} \cdot \mathrm{diHCl} \mathrm{eq} \cdot \mathrm{kg}^{-1}$ for $\mathrm{C} 1$ in mussel matrix to $0.057 \mathrm{mg}$ STX. diHCl eq. $\mathrm{kg}^{-1}$ for GTX1 in oyster matrix.

Limits of quantification (LOQs) are also summarized in Table 2, ranging from 0.0001 to $0.0750 \mathrm{mg}$ $\mathrm{STX} \cdot \mathrm{diHCl} \mathrm{eq} \cdot \mathrm{kg}^{-1}$. The values for dcNEO in oyster and in scallop were the highest, which might be due to the low intensity of the toxin fluorescence signal response.

For the majority of toxins, the values obtained were improved with regard to those reported by previously published LC-fluorescence methods [11,22]; therefore, they showed a good detection and quantitation capability for regulatory purposes. 
Table 1. Toxin linearity results: calibration curve equations and the corresponding correlation coefficients.

\begin{tabular}{cccccc}
\hline \multirow{2}{*}{ Compound } & \multicolumn{2}{c}{ Range in $\mathbf{~ m g} \cdot \mathbf{~ k g}^{\mathbf{- 1}}$} & \multicolumn{2}{c}{ Range in $\mathbf{~ m g ~ S T X \cdot d i H C l ~ ~ k g ^ { - 1 }}$} & \multirow{2}{*}{ Correlation $(\boldsymbol{r})$} \\
\cline { 2 - 4 } & Lower & Upper & Lower & Upper & \\
\hline dcNEO & 0.021 & 1.33 & 0.009 & 0.575 & 0.9935 \\
dcSTX & 0.003 & 3.28 & 0.002 & 2.443 & 0.9849 \\
dcGTX3 & 0.004 & 1.03 & 0.001 & 0.408 & 0.9987 \\
STX & 0.007 & 3.81 & 0.007 & 3.812 & 0.9950 \\
NEO & 0.052 & 1.66 & 0.046 & 1.816 & 0.9937 \\
GTX5 & 0.160 & 2.62 & 0.010 & 0.165 & 0.9937 \\
dcGTX2 & 0.002 & 4.37 & 0.0003 & 0.710 & 0.9982 \\
GTX3 & 0.032 & 1.02 & 0.019 & 0.612 & 0.9986 \\
GTX4 & 0.0007 & 1.28 & 0.0005 & 0.841 & 0.9911 \\
GTX1 & 0.004 & 3.95 & 0.004 & 3.554 & 0.9994 \\
C2 & 0.006 & 1.44 & 0.0005 & 0.109 & 0.9969 \\
GTX2 & 0.043 & 2.77 & 0.014 & 0.934 & 0.9981 \\
C1 & 0.157 & 5.01 & 0.0007 & 0.024 & 0.9980 \\
\hline
\end{tabular}

Table 2. Limits of detection (LOD) and quantification (LOQ) for each toxin in each matrix (as mg STX $\cdot \mathrm{diHCl} \mathrm{kg}^{-1}$ ).

\begin{tabular}{cccccccccccccccc}
\hline \multicolumn{2}{c}{ Matrix } & dcNEO & dcSTX & dcGTX3 & STX & NEO & GTX5 & dcGTX2 & GTX3 & GTX4 & GTX1 & C2 & GTX2 & C1 & ( \\
\multirow{2}{*}{ Mussel } & LOD & 0.0045 & 0.0004 & 0.0006 & 0.0044 & 0.0093 & 0.0027 & 0.0001 & 0.0012 & 0.0015 & 0.0037 & 0.0003 & 0.0001 & 0.0002 \\
& LOQ & 0.0070 & 0.0007 & 0.0019 & 0.0055 & 0.0163 & 0.0099 & 0.0003 & 0.0113 & 0.0059 & 0.0117 & 0.0007 & 0.0138 & 0.0005 \\
\hline \multirow{2}{*}{ Clam } & LOD & 0.0030 & 0.0003 & 0.0035 & 0.0041 & 0.0059 & 0.0007 & 0.0007 & 0.0114 & 0.0010 & 0.0008 & 0.0024 & 0.0043 & 0.0004 \\
& LOQ & 0.0040 & 0.0004 & 0.0035 & 0.0047 & 0.0078 & 0.0012 & 0.0014 & 0.0136 & 0.0026 & 0.0032 & 0.0027 & 0.0070 & 0.0005 \\
\hline \multirow{2}{*}{ Scallop } & LOD & 0.0344 & 0.0003 & 0.0002 & 0.0038 & 0.0054 & 0.0002 & 0.0004 & 0.0007 & 0.0007 & 0.0005 & 0.0001 & 0.0005 & 0.0001 \\
& LOQ & 0.0750 & 0.0004 & 0.0005 & 0.0039 & 0.0065 & 0.0007 & 0.0010 & 0.0018 & 0.0019 & 0.0011 & 0.0001 & 0.0012 & 0.0001 \\
\hline \multirow{2}{*}{ Oyster } & LOD & 0.0330 & 0.0003 & 0.0106 & 0.0039 & 0.0053 & 0.0069 & 0.0253 & 0.0062 & 0.0004 & 0.0016 & 0.0035 & 0.0366 & 0.0008 \\
& LOQ & 0.0750 & 0.0004 & 0.0111 & 0.0042 & 0.0065 & 0.0087 & 0.0258 & 0.0074 & 0.0009 & 0.0043 & 0.0037 & 0.0420 & 0.0008 \\
\hline
\end{tabular}


The repeatability of the method for each toxin was calculated, and the results are summarized in Table 3. The RSD percentages (\%RSD) for all toxins were within the acceptable range, as indicated by IUPAC (International Union of Pure and Applied Chemistry) [47]. The highest variations appeared in dcNEO for all tested matrices at low concentrations, which can be due to its low fluorescence signal. The rest of the toxins gave relatively consistent values, except for the oyster matrix, which showed the highest variations. Despite this, replicate injections of sample tissue extract solutions indicated good peak response repeatability over the range of concentrations studied; the \%RSD ranged from $1.6 \%-9.4 \%$.

Retention times were stable, and the \%RSD varied from $0.1 \%-0.9 \%$ (Table 4 ). The order of elution for C2 and GTX2 toxins changed after column regeneration: initially, the elution order was GTX2 and C2 (as can be seen in Figures 1 and 2), and after regeneration, the order of elution was inverted: C2 eluted before GTX2, and it remained the same after successive regenerations (Figure 3). Approximately 600 samples could be analyzed before the regeneration of the column, and a total of 6000 injections were possible, which is 10-times more than what is possible with PCOX columns. Although it could be seen as a lack of reproducibility and reliability of the column, Table 4 shows that the \%RSD of retention times were very low. Therefore, it should not be considered as a lack of reproducibility, but since this may be perceived as a source of confusion, an easy solution would be to treat the column before its first use with a regenerative process, since it does not shorten its working life. Figure 3 shows the separation accomplished for PST after regeneration of the column. All of the validation parameters obtained in this work were made with the regenerated column. After this treatment, the elution order was stable. We also tested the validation parameters in a new column before regeneration, and all of the values matched those obtained after the regeneration.

Some guidance documents request the determination of the recovery for the lowest and highest concentrations [48,49] or even specify that the recovery should be above 50\% [48]. According to other authors [50], the acceptable range of recovery depends on the concentration; in this study, the concentration varied between $0.02 \mathrm{mg} \cdot \mathrm{kg}^{-1}$ and $0.1 \mathrm{mg} \cdot \mathrm{kg}^{-1}$, and the acceptable mean recovery percentage range was $70 \%-120 \%$. Table 5 summarizes the mean recovery percentages of PST in mussel, clam, scallop and oyster matrices. The recoveries of dcNEO and dcGTX3 in all matrices were circa $67 \%$ and $66 \%$, respectively, which were slightly below the values for the rest of the toxins. Moreover, the matrix that gave the lowest results was oyster, whose values for six toxins were slightly below the acceptable range established between $70 \%$ and $120 \%$. Very important, along with the values of recovery, is the repeatability, and the observed \%RSD data values indicated that it was satisfactory.

In addition to validation information about PST analysis with a porous graphite column and the improvement that implies its use to analyze PST, we also propose a modification of this method to include the analysis of TTX because of its appearance in marine environments together with those toxins. Although it could be adequate to propose only one method to analyze PST and TTX, we think that it is more convenient to have one method for PST and a modification of it to include TTX, because they belong to different groups of toxins. Figure 5 shows the separation of all toxins in one analysis, where the gradient elution had to be changed with regard to PST separation, as is described in the Materials and Methods (Section 4.4). In this way, two methods are developed that allow one to determine either PST or PST along with TTX. 
Table 3. \%RSD (Relative Standard Deviation) values for the repeatability of the method.

\begin{tabular}{|c|c|c|c|c|c|c|c|c|c|c|c|c|c|c|}
\hline mg STX.diHCl kg ${ }^{-1}$ & Matrix & dcNEO & dcSTX & dcGTX3 & STX & NEO & GTX5 & dcGTX2 & GTX3 & GTX4 & GTX1 & $\mathrm{C} 2$ & GTX2 & $\mathrm{C1}$ \\
\hline \multirow{4}{*}{0.2} & Mussel & 7.7 & 5.1 & 2.7 & 4.7 & 8.7 & 6.4 & 5.9 & 3.8 & 2.4 & 2.9 & 4.0 & 4.6 & 5.6 \\
\hline & Clam & 6.8 & 3.9 & 2.0 & 4.7 & 5.7 & 6.2 & 5.1 & 5.7 & 3.6 & 3.6 & 6.5 & 6.9 & 5.5 \\
\hline & Scallop & 8.4 & 5.8 & 2.3 & 6.3 & 5.7 & 6.0 & 1.4 & 3.9 & 6.4 & 8.0 & 9.4 & 4.9 & 6.5 \\
\hline & Oyster & 7.3 & 4.6 & 5.8 & 7.8 & 9.0 & 9.1 & 1.8 & 4.9 & 5.0 & 4.7 & 6.5 & 4.3 & 5.2 \\
\hline \multirow{4}{*}{0.8} & Mussel & 3.9 & 4.6 & 3.6 & 5.3 & 4.8 & 2.8 & 5.7 & 4.4 & 5.5 & 2.7 & 6.1 & 5.5 & 4.1 \\
\hline & Clam & 6.0 & 6.4 & 3.6 & 5.3 & 5.8 & 6.7 & 3.1 & 7.0 & 4.7 & 2.0 & 3.6 & 5.8 & 3.4 \\
\hline & Scallop & 6.2 & 3.2 & 1.8 & 5.5 & 2.1 & 6.0 & 5.4 & 5.2 & 5.5 & 4.8 & 7.8 & 3.3 & 2.2 \\
\hline & Oyster & 8.6 & 1.6 & 1.7 & 7.1 & 6.6 & 8.8 & 6.4 & 4.5 & 2.6 & 5.3 & 3.3 & 4.3 & 2.7 \\
\hline \multirow{4}{*}{1.6} & Mussel & 2.3 & 4.3 & 6.4 & 5.6 & 4.5 & 1.7 & 2.6 & 4.7 & 5.4 & 2.1 & 4.6 & 2.7 & 3.7 \\
\hline & Clam & 5.2 & 3.3 & 4.6 & 3.9 & 5.1 & 2.9 & 2.9 & 6.0 & 5.6 & 2.4 & 4.2 & 6.3 & 4.1 \\
\hline & Scallop & 4.4 & 4.9 & 5.4 & 6.8 & 4.4 & 2.4 & 3.7 & 3.4 & 6.1 & 2.6 & 3.9 & 5.4 & 3.6 \\
\hline & Oyster & 2.5 & 2.4 & 3.5 & 5.9 & 5.2 & 2.5 & 2.7 & 2.8 & 3.1 & 2.0 & 6.5 & 4.6 & 5.6 \\
\hline
\end{tabular}

Table 4. \%RSD values for the retention times (RT) of repeated injections of the PST (Paralytic Shellfish Toxins) standard solutions.

\begin{tabular}{|c|c|c|c|c|c|c|c|c|c|c|c|c|c|c|}
\hline mg STX.diHCl kg kg $^{-1}$ & Matrix & dcNEO & dcSTX & dcGTX3 & STX & NEO & GTX5 & dcGTX2 & GTX3 & GTX4 & GTX1 & $\mathrm{C} 2$ & GTX2 & C1 \\
\hline \multirow{4}{*}{0.2} & Mussel & 0.8 & 0.6 & 0.3 & 0.8 & 0.8 & 0.7 & 0.6 & 0.5 & 0.4 & 0.3 & 0.4 & 0.4 & 0.2 \\
\hline & Clam & 0.5 & 0.4 & 0.8 & 0.7 & 0.7 & 0.3 & 0.5 & 0.5 & 0.5 & 0.2 & 0.4 & 0.3 & 0.3 \\
\hline & Scallop & 0.9 & 0.2 & 0.3 & 0.2 & 0.3 & 0.3 & 0.2 & 0.3 & 0.6 & 0.3 & 0.2 & 0.2 & 0.2 \\
\hline & Oyster & 0.5 & 0.2 & 0.3 & 0.3 & 0.3 & 0.3 & 0.2 & 0.2 & 0.2 & 0.3 & 0.2 & 0.2 & 0.2 \\
\hline \multirow{4}{*}{0.8} & Mussel & 0.6 & 0.5 & 0.4 & 0.1 & 0.2 & 0.3 & 0.3 & 0.3 & 0.3 & 0.6 & 0.2 & 0.2 & 0.5 \\
\hline & Clam & 0.8 & 0.6 & 0.4 & 0.5 & 0.5 & 0.3 & 0.3 & 0.3 & 0.3 & 0.5 & 0.2 & 0.2 & 0.4 \\
\hline & Scallop & 0.3 & 0.5 & 0.5 & 0.4 & 0.4 & 0.3 & 0.3 & 0.3 & 0.4 & 0.5 & 0.2 & 0.3 & 0.4 \\
\hline & Oyster & 0.7 & 0.8 & 0.7 & 0.7 & 0.8 & 0.8 & 0.7 & 0.6 & 0.4 & 0.6 & 0.3 & 0.1 & 0.4 \\
\hline \multirow{4}{*}{1.6} & Mussel & 0.7 & 0.6 & 0.4 & 0.5 & 0.4 & 0.7 & 0.8 & 0.4 & 0.7 & 0.5 & 0.5 & 0.5 & 0.8 \\
\hline & Clam & 0.9 & 0.4 & 0.4 & 0.8 & 0.7 & 0.3 & 0.7 & 0.5 & 0.5 & 0.9 & 0.5 & 0.8 & 0.8 \\
\hline & Scallop & 0.3 & 0.4 & 0.3 & 0.4 & 0.5 & 0.7 & 0.2 & 0.5 & 0.6 & 0.5 & 0.7 & 0.6 & 0.8 \\
\hline & Oyster & 0.8 & 0.7 & 0.6 & 0.8 & 0.2 & 0.6 & 0.8 & 0.8 & 0.8 & 0.8 & 0.5 & 0.6 & 0.8 \\
\hline
\end{tabular}


Table 5. Percentage of recovery ( 3 days, 5 replicates, $n=15)$ from all toxins in four matrices (mussels, clams, scallops and oysters).

\begin{tabular}{|c|c|c|c|c|c|c|c|c|c|c|c|c|c|c|}
\hline & Spiked Matrix & dcNEO & dcSTX & dcGTX3 & STX & NEO & GTX5 & dcGTX2 & GTX3 & GTX4 & GTX1 & $\mathrm{C} 2$ & GTX2 & $\mathrm{C} 1$ \\
\hline Matrix & Spiked level, $\mathrm{mg} \cdot \mathrm{kg}^{-1}$ & 0.08 & 0.03 & 0.02 & 0.04 & 0.09 & 0.16 & 0.08 & 0.05 & 0.02 & 0.06 & 0.03 & 0.13 & 0.10 \\
\hline \multirow{2}{*}{ Mussel } & Recovery\% & 65.8 & 82.4 & 65.2 & 83.4 & 72 & 85.8 & 87.8 & 84.2 & 76.2 & 79.2 & 76 & 73.2 & 78 \\
\hline & $\%$ RSD & 4.7 & 5.4 & 3.0 & 7.0 & 6.4 & 7.7 & 9.3 & 9.3 & 1.6 & 1.5 & 8.9 & 5.4 & 2.9 \\
\hline \multirow{2}{*}{ Clam } & Recovery\% & 63.6 & 92.6 & 67.8 & 78.8 & 72.8 & 86.2 & 84 & 77.6 & 73 & 75.4 & 68.2 & 83 & 74.6 \\
\hline & $\%$ RSD & 2.9 & 3.6 & 1.9 & 2.6 & 2.6 & 4.0 & 8.8 & 4.0 & 2.9 & 3.5 & 2.2 & 4.2 & 3.8 \\
\hline \multirow{2}{*}{ Scallop } & Recovery\% & 72 & 88.2 & 69 & 80.2 & 72 & 84.6 & 118.6 & 78.6 & 74.4 & 73.8 & 75.2 & 82.6 & 73.8 \\
\hline & $\%$ RSD & 2.1 & 1.3 & 1.2 & 1.9 & 2.5 & 2.9 & 1.7 & 1.5 & 3.6 & 4.1 & 2.9 & 4.0 & 2.5 \\
\hline \multirow{2}{*}{ Oyster } & Recovery\% & 68.6 & 78.2 & 63.6 & 79.2 & 74.4 & 72.4 & 80 & 69.8 & 73.2 & 76 & 66.2 & 67.2 & 62.6 \\
\hline & \%RSD & 2.5 & 1.9 & 5.8 & 4.6 & 4.3 & 3.5 & 1.9 & 3.1 & 1.6 & 4.0 & 3.0 & 2.6 & 2.2 \\
\hline
\end{tabular}

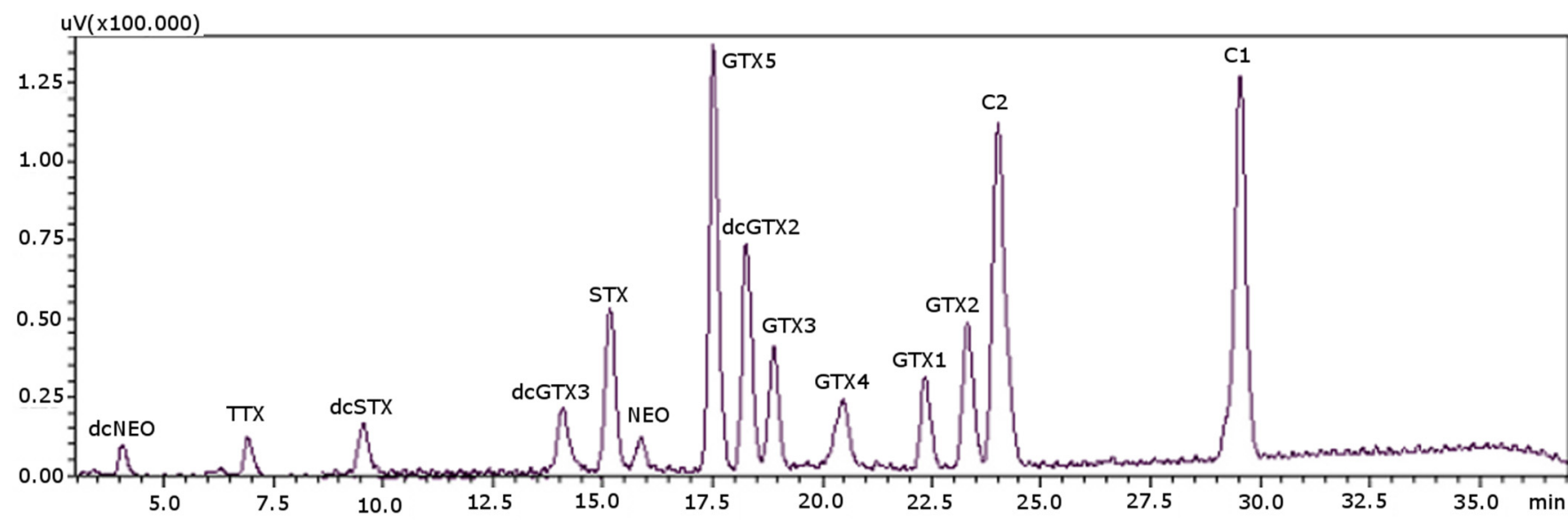

Figure 5. Chromatographic separation of PST and tetrodotoxin (TTX) standards with the post-column oxidation method, using a porous graphitic carbon column. Concentrations used for the PST standards (as mg STX.diHCl eq $\cdot \mathrm{kg}^{-1}$ ): 0.0978 for dcNEO, 0.0251 for dcSTX, 0.0040 for dcGTX3, 0.3945 for STX, 0.4265 for NEO, 0.0017 for GTX5, 0.0005 for dcGTX2, 0.0277 for GTX3, 0.0020 for GTX4, 0.0094 for GTX1, 0.0249 for GTX2, 0.0002 for C1 and 0.0010 for C2; concentration of TTX standard $(\mu \mathrm{M})$ : 68.6. 
For TTX, the recovery percentage, as well as LOD and LOQ were calculated for spiked mussel matrix. The recovery percentage $(74.7 \% \pm 1.5 \%)$ was determined analyzing five replicates of spiked mussel matrix: it was calculated at one level of concentration $\left(16.747 \mathrm{mg} \cdot \mathrm{kg}^{-1}\right)$ that was approximately in the middle of the linearity range. The linearity range was between 10.306 and $21.900 \mathrm{mg} \cdot \mathrm{kg}^{-1}$ $(r=0.9953)$. LOD and LOQ values (in $\mu \mathrm{g} \cdot \mathrm{mL}^{-1}$ ) were 3.7957 and 10.7304 , respectively.

LOD and LOQ data were higher than those obtained by LC-MS/MS, where they are in the range of $\mathrm{ng} \cdot \mathrm{mL}^{-1}$ [29], and this was due to the low fluorescence signal of TTX. It is possible to improve the limit of detection for TTX with the use of a more sophisticated fluorescence detection system (i.e., with double excitation fluorimeters); although, as we report now, LOD and LOQ of TTX do not allow using this method for TTX regulatory purposes. Nonetheless, it shows that all toxins can be separated and detected in one single injection, improving considerably the current methods. The recovery percentage was within the acceptable range (70\%-120\%) [50], and although TTX is being found in new matrices, the matrix used in this work was mussel, because it was amenable to contain both PST and TTX, as already reported [27].

In previous works [51,52], TTX and PST were identified simultaneously by using the post-column oxidation method [20], but as happens with PST, they were not analyzed in one single injection. In this work, the only modification regarding the method proposed for PST was the variation in gradient program, because otherwise, dcNEO and TTX would coelute. Therefore, 14 toxins, belonging to two different groups, were separated and analyzed: PST and TTX. The run time of $37 \mathrm{~min}$ (which includes the 7-min equilibration time) is suitable for a chromatographic separation, and in this way, the possibility of misidentification for TTX in regard to PST was sorted out. As there is no commercial certified standard available for TTX analogues, it was not possible to analyze them.

\section{Conclusions}

This work describes a liquid-chromatography method with fluorescence detection to analyze PSTs and a variation to analyze also TTX and PST. The first one allowed the separation and quantitation of all PST available as commercial standards, in one single run and in an adequate time: 13 analogues were analyzed in $37 \mathrm{~min}$. It was based on the use of a porous graphitized column with good properties related to separation performance and robustness. This method contributes to improve the analytical methodology for separation and quantitation of PST.

The second method was a modification of the first one, where the gradient elution was changed, allowing one to see in one run 13 commercial standards of PST alongside TTX. This improved the separation of those toxins, being the first time that they were analyzed all together in one single run. This method enables one to analyze them more easily due to the more frequent appearance of TTX in marine waters, where they were not seen before, because of global warming.

\section{Materials and Methods}

\subsection{Chemicals}

HPLC-grade methanol and acetonitrile, analytical reagent-grade sodium hydroxide, periodic acid, hydrochloric acid $37 \%$, ortho-phosphoric acid $85 \%$, nitric acid $65 \%$, trifluoroacetic acid (TFA), dichloromethane, tetrahydrofuran and ammonium acetate were all from Panreac Química S.A., Barcelona, Spain. Trichloroacetic acid and triethylamine were purchased from Sigma Aldrich (Madrid, Spain). Only HPLC-grade water was used to prepare reagent solutions.

Certified standards provided by Cifga S.A. (Lugo, Spain) were: saxitoxin (STX), neosaxitoxin (NEO), decarbamoyl-saxitoxin (dcSTX), gonyautoxin 5 (GTX5), gonyautoxins 1 and 4 (GTX1,4), gonyautoxins 2 and 3 (GTX2,3), decarbamoyl-gonyautoxins 2 and 3 (dcGTX2,3), N-sulfocarbamoyl-gonyautoxins 2 and 3 (C1 and C2) and tetrodotoxin (TTX); decarbamoyl-neosaxitoxin (dcNEO) was obtained from NRC (Halifax, NS, Canada).

Commercial toxin-free shellfish samples of mussel (Mytillus galloprovincialis), clam (Pecten maximus), scallop (Ruditapes decussatus) and oyster (Ostrea edulis) were used. 


\subsection{Instrumentation}

The chromatographic setup from Shimadzu (Izasa, Barcelona, Spain) included a binary LC-10ADVP pump system, autoinjector SIL-20AC with a refrigerated rack at $6{ }^{\circ} \mathrm{C}$, column oven CTO-20AC, a fluorescence detector RF-10AXL and the system controller CBM-20A. The post-column reaction system was formed by a knitted reaction coil of $1 \mathrm{~mL}(5 \mathrm{~m} \times 0.50 \mathrm{~mm}$ i.d., Supelco, Madrid, Spain) immersed in a water bath at $75^{\circ} \mathrm{C}$ and two post-column pumps LC-20AD and LC-6A, respectively, from Shimadzu (Izasa, Barcelona, Spain). The separation and identification of toxins was achieved in a porous graphitic carbon Hypercarb ${ }^{\circledR}$ column (i.d. $4.6 \mathrm{~mm} \times 100 \mathrm{~mm}, 5-\mu \mathrm{m}$ particle size, Part Number 35005-104630) from Thermo (Fisher Scientific, Madrid, Spain), inside the column oven at $20^{\circ} \mathrm{C}$.

\subsection{Samples Extraction and Clean-Up}

The protocol according to the PCOX method [22] was applied for the extraction of PST from shellfish material. A 5-g sample was homogenized with $5 \mathrm{~mL}$ of $0.1 \mathrm{M} \mathrm{HCl}$ using a vortex mixer. The $\mathrm{pH}$ of the mixture, which should be, according to the official protocol, between 2 and 4, was adjusted to 3 [41]. If necessary, the $\mathrm{pH}$ was adjusted while mixing by adding dropwise $5 \mathrm{M} \mathrm{HCl}$ to lower the $\mathrm{pH}$ or $0.1 \mathrm{M} \mathrm{NaOH}$ to raise the $\mathrm{pH}$. The tube was placed in a boiling water bath for $5 \mathrm{~min}$, removed and allowed to cool down to room temperature. The $\mathrm{pH}$ was again adjusted to 3 when necessary. The mixture was centrifuged at $3000 \times \mathrm{g}$ for $10 \mathrm{~min}$ and the supernatant decanted.

Samples were deproteinated by adding $25 \mu \mathrm{L}$ of $30 \%\left(w \cdot v^{-1}\right)$ trichloroacetic acid to $500 \mu \mathrm{L}$ shellfish extract, mixed in a vortex and centrifuged at $16,000 \times g$ for $5 \mathrm{~min}$. Then, $40 \mu \mathrm{L}$ of $1.0 \mathrm{M} \mathrm{NaOH}$ were added, mixed and centrifuged at 16,000 $\times g$ for 5 min [22]. The sample was then extracted with $500 \mu \mathrm{L}$ of dichloromethane, mixed in a vortex and the aqueous and organic phases separated by gravity.

The aqueous phase was cleansed using a Hypersep Hypercarb ${ }^{\circledR}$ (PGC) SPE cartridge (200 $\mathrm{mg}^{-1} \mathrm{~mL}^{-1}$ ) (Thermo Fisher Scientific, Madrid, Spain), which was previously conditioned with $3 \mathrm{~mL}$ of $80 \%\left(v \cdot v^{-1}\right)$ dichloromethane:methanol, $3 \mathrm{~mL}$ of methanol and $3 \mathrm{~mL}$ of $0.1 \mathrm{M}$ ammonium acetate. A $500-\mu \mathrm{L}$ extract was then loaded and washed with $11 \mathrm{~mL}$ of $0.1 \mathrm{M}$ ammonium acetate. The PST were eluted with $500 \mu \mathrm{L}$ of citrate buffer in $10 \%\left(v \cdot v^{-1}\right)$ acetonitrile.

The same extraction and clean-up procedures were used when TTX was analyzed, and for this toxin, the seafood material was only mussel matrix.

\subsection{Development of HPLC and PCOX Fluorescence Detection}

The key parameters to be controlled were: the oxidant flowrate, acid flowrate, column temperature, reaction temperature, percentage of TFA and percentage of organic modifier. They were all tested to improve peak shape, resolution and sensitivity.

The final conditions recommended for routine operation were the following: all of the toxins were separated using a $100 \mathrm{~mm} \times 4.6 \mathrm{~mm}$ i.d., 5- $\mu \mathrm{m}$ Hypercarb ${ }^{\circledR}$ column (Thermo, Fisher Scientific, Madrid, Spain) with the column oven at $20{ }^{\circ} \mathrm{C}$. Solvent A is $0.075 \%\left(v \cdot v^{-1}\right)$ TFA in water; Solvent B is $0.025 \%$ $\left(v \cdot v^{-1}\right)$ TFA in $50 \%\left(v \cdot v^{-1}\right)$ acetonitrile:water. The flowrate was set at $0.8 \mathrm{~mL} \cdot \mathrm{min}^{-1}$, and the injection volume was $5 \mu \mathrm{L}$. The gradient conditions for PST were: start at 4\% B, 4\%-25\% B in 30 min (linear slope), back to $4 \% \mathrm{~B}$ at $30.01 \mathrm{~min}$ and at $4 \% \mathrm{~B}$ for $7 \mathrm{~min}$ before the next injection. For TTX the gradient was: start at $0 \% \mathrm{~B}, 0 \%-15 \% \mathrm{~B}$ in $10 \mathrm{~min}, 15 \%-35 \% \mathrm{~B}$ in the next $12 \mathrm{~min}$, back to $0 \% \mathrm{~B}$ at $32.01 \mathrm{~min}$ and $0 \% \mathrm{~B}$ for $5 \mathrm{~min}$ before the next injection.

The column eluate was mixed into a tee connector with the oxidant $100 \mathrm{mM} \mathrm{H}_{3} \mathrm{PO}_{4}, 5 \mathrm{mM} \mathrm{H}_{5} \mathrm{IO}_{6}$, adjusted at $\mathrm{pH} 7.8$ with $5 \mathrm{M} \mathrm{NaOH}$, at a flow rate of $0.5 \mathrm{~mL} \cdot \mathrm{min}^{-1}$. The resulting mixture was heated while passing through a 1-mL knitted Teflon reactor coil ( $5 \mathrm{~m} \times 0.50 \mathrm{~mm}$ i.d., Supelco, Madrid, Spain) immersed in a water bath at $75^{\circ} \mathrm{C}$. It was then acidified in another tee connector with $0.1 \mathrm{M} \mathrm{HNO}_{3}$ at a flow rate of $0.3 \mathrm{~mL} \cdot \mathrm{min}^{-1}$, to reach a detector outflow $\mathrm{pH}$ that should range between 5 and 7 [17]. The fluorescent eluted derivatives were monitored using a fluorescence detector at 330- and 395-nm excitation and emission wavelengths, respectively. 


\subsection{Method Validation}

Method validation parameters were calculated for the separation of PST. Linearity was calculated by injecting mixtures of all standards at different concentrations in each selected matrix. The correlation coefficient $(r)$ must not be lower than 0.99 , as was recommended [53,54], and the results $[22,23]$ were expressed as $\mathrm{mg} \mathrm{STX} \cdot \mathrm{diHCl} \mathrm{eq} \cdot \mathrm{kg}^{-1}$, where the toxicity equivalent factors (TEF) were taken from Oshima [20]. Results were obtained by mathematical treatment of the analysis data for each toxin at different concentrations, in the same manner as other authors have done previously [22,23].

The limit of detection (LOD) was determined for each matrix (mussel, clam, scallop and oyster) analyzing five replicate extracts of blank matrix repeated over 6 days $(n=30)$, calculating the signal-to-noise ratio at the corresponding retention time for each toxin, multiplying it by 3 and converting it into $\mathrm{mg} \mathrm{STX} \cdot \mathrm{diHCl} \mathrm{eq} \cdot \mathrm{kg}^{-1}$, as was mentioned before. The limit of quantitation (LOQ) was calculated multiplying LOD by a factor of 3 [50]. The limits of quantitation were also confirmed by spiking the blank matrices with the standards at the concentration of the calculated LOQ; the solutions were diluted until the signal-to-noise ratio was below 3, which corresponds to the limit of detection, and then multiplying it by 3 to obtain the limits of quantitation.

Repeatability was calculated for each matrix at 3 different levels of concentration $(0.2 \mathrm{mg}$ $\mathrm{STX} \cdot \mathrm{diHCl} \mathrm{eq} \cdot \mathrm{kg}^{-1}, 0.8 \mathrm{mg} \mathrm{STX} \cdot \mathrm{diHCl} \mathrm{eq} \cdot \mathrm{kg}^{-1}$ and $1.6 \mathrm{mg} \mathrm{STX} \cdot \mathrm{diHCl} \mathrm{eq} \cdot \mathrm{kg}^{-1}$ ). Five replicates were analyzed and repeated over 3 days $(n=15)$, for each matrix at each concentration and for each standard. The same injections were used to calculate the retention times' relative standard deviations (\%RSD) for each toxin.

The percentage of recovery was determined analyzing five replicates repeated over 3 days for all toxins and matrices. This parameter was calculated at one level of concentration in each spiked matrix.

For TTX, when it was analyzed with the rest of PST in mussel matrix, the validation parameters were obtained as follows: linearity was calculated by injecting TTX standards diluted in water at different concentrations, ranging from 10.306 to $21.900 \mathrm{mg} \cdot \mathrm{kg}^{-1}$; LOD was determined for mussel matrix by the analysis of five replicate extracts of blank matrix repeated over 6 days $(n=30)$, calculating the signal-to-noise ratio at the corresponding retention time for TTX and multiplying it by 3 . LOQ was calculated by multiplying the LOD by a factor of 3 [50]. Recovery was calculated by the analysis of five replicate extracts of spiked mussel matrix, at one level of concentration.

\subsection{Regeneration of Hypercarb Column and SPE Cartridges}

To avoid TFA saturation in the Hypercarb ${ }^{\circledR}$ column, water was run through it when the equipment was in standby mode. TFA can be adsorbed on the surface of porous graphitic carbon; therefore, after using this additive in the mobile phase, a regeneration of the column was undertaken to ensure the original Hypercarb ${ }^{\circledR}$ selectivity of the column and that optimum performance was accomplished. Acid/base regeneration was suitable for ionized species being chromatographed in strongly-aqueous eluents. The regeneration recommended by the manufacturer [40] was as follows: the column was inverted at a flow rate of $1 \mathrm{~mL} \cdot \mathrm{min}^{-1}$ with $50 \mathrm{~mL}$ of $50 \%\left(v \cdot v^{-1}\right)$ tetrahydrofuran solution containing $0.1 \%\left(v \cdot v^{-1}\right)$ TFA, then flushed at $1 \mathrm{~mL} \cdot \mathrm{min}^{-1}$ with $50 \mathrm{~mL}$ of $50 \%\left(v \cdot v^{-1}\right)$ tetrahydrofuran solution containing $0.1 \%$ triethylamine or sodium hydroxide, followed by $50 \mathrm{~mL}$ of $50 \%\left(v \cdot v^{-1}\right)$ tetrahydrofuran solution containing $0.1 \%\left(v \cdot v^{-1}\right)$ TFA at a flow rate of $1 \mathrm{~mL} \cdot \mathrm{min}^{-1}$. Finally, 95\% $\left(v \cdot v^{-1}\right)$ methanol was eluted to re-equilibrate and re-invert the column. Before working back with the column, it was advisable to pump water through it overnight to remove any traces of solvents.

This regeneration was also useful for Hypercarb ${ }^{\circledR}$ cartridges if they stop functioning, although this cartridge is stable throughout the entire $\mathrm{pH}$ range from 1-14, and it is not affected by aggressive

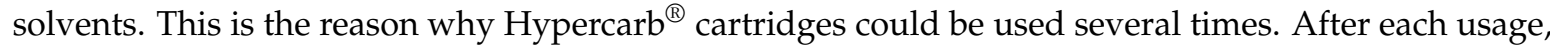
they were washed with water to remove citrate buffer. When this cleaning procedure was not enough, a thorough cleansing was made with more aggressive solvents. 
Acknowledgments: The research leading to these results has received funding from the following FEDER cofunded-grants. From CDTI and Technological Funds, supported by Ministerio de Economía y Competitividad, AGL2012-40185-CO2-01, AGL2014-58210-R, Xunta de Galicia Axencia Galega de Innovación, ITC-20133020 SINTOX, and Consellería de Cultura, Educación e Ordenación Universitaria, GRC2013-016. From CDTI under ISIP Programme, Spain, IDI-20130304 APTAFOOD. From the European Union's Seventh Framework Programme managed by REA-Research Executive Agency (FP7/2007-2013) under grant agreement 312184 PHARMASEA.

Author Contributions: A.M.B., M.A., A.A. and L.M.B. conceived and designed the experiments; V.R. A.M.B., M.A., A.A. performed the experiments; V.R., A.M.B., A.A. analyzed the data; M.A. and A.A. contributed reagents/materials/analysis tools; V.R., A.M.B. and L.M.B. wrote the paper.

Conflicts of Interest: The authors declare no conflict of interest.

\section{References}

1. Daneshian, M.; Botana, L.M.; Dechraoui Bottein, M.Y.; Buckland, G.; Campas, M.; Dennison, N.; Dickey, R.W.; Diogene, J.; Fessard, V.; Hartung, T.; et al. A roadmap for hazard monitoring and risk assessment of marine biotoxins on the basis of chemical and biological test systems. ALTEX 2013, 30, 487-545. [CrossRef] [PubMed]

2. Van Dolah, F.M. Marine algal toxins: Origins, health effects, and their increased occurrence. Environ. Health Perspect. 2000, 108, 133-141. [CrossRef] [PubMed]

3. Bricelj, V.M.; Shumway, S.E. Paralytic Shellfish Toxins in Bivalve Molluscs: Occurrence, Transfer Kinetics, and Biotransformation. Rev. Fish. Sci. 1998, 6, 315-383. [CrossRef]

4. Vlamis, A.; Katikou, P. Ecobiology and geographical distribution of potentially toxic marine dinoflagellates. In Seafood and Freshwater Toxins: Pharmacology, Physiology and Detection, 3rd ed.; Botana, L.M, Ed.; CRC Press: Boca Raton, FL, USA, 2014; pp. 569-625.

5. Dell'Aversano, C.; Walter, J.A.; Burton, I.W.; Stirling, D.J.; Fattorusso, E.; Quilliam, M.A. Isolation and structure elucidation of new and unusual saxitoxin analogues from mussels. J. Nat. Prod. 2008, 71, 1518-1523. [CrossRef] [PubMed]

6. Wiese, M.; D’ Agostino, P.M.; Mihali, T.K.; Moffitt, M.C.; Neilan, B.A. Neurotoxic Alkaloids: Saxitoxin and its Analogs. Mar. Drugs 2010, 8, 2185-2211. [CrossRef] [PubMed]

7. Sullivan, J.J.; Wekell, M.M. Determination of paralytic shellfish poisoning toxins by high pressure liquid chromatography. In Seafood Toxins; Ragelis, E.P., Ed.; American Chemical Society: Washington, DC, USA, 1984.

8. Humpage, A.R.; Magalhaes, V.F.; Froscio, S.M. Comparison of analytical tools and biological assays for detection of paralytic shellfish poisoning toxins. Anal. Bioanal. Chem. 2010, 397, 1655-1671. [CrossRef] [PubMed]

9. Lawrence, J.F.; Niedzwiadek, B. Quantitative Determination of Paralytic Shellfish Poisoning Toxins in Shellfish by Using Prechromatographic Oxidation and Liquid Chromatography with Fluorescence Detection. J. AOAC Int. 2001, 84, 1099-1108. [PubMed]

10. Thomas, K.M.; Chung, S.; Ku, J.; Reeves, K.; Quilliam, M.A. Analysis of PSP toxins by liquid chromatography with post column oxidation and fluorescence detection. In Molluscan Shellfish Safety; Henshilwood, K., McMahon, B.D.T., Cusack, C., Keaveney, S., Silke, J., O'Cinneide, M., Lyons, D., Hess, P., Eds.; The Marine Institute: Galway, Ireland, 2006; pp. 63-122.

11. Lawrence, J.F.; Niedzwiadek, B.; Menard, C. Quantitative Determination of Paralytic Shellfish Poisoning Toxins in Shellfish Using Prechromatographic Oxidation and Liquid Chromatography with Fluorescence Detection: Collaborative Study. J. AOAC Int. 2005, 88, 1714-1732. [PubMed]

12. AOAC. Method 2005.06: Paralytic Shellfish Poisoning Toxins in Shellfish. Prechromatographic Oxidation and Liquid Chromatography with Fluorescence Detection. In Official Methods of Analysis of the Association of Official Analytical Chemists, 1st ed.; AOAC: Gaithersburg, MD, USA, 2005.

13. Turner, A.D.; Hatfield, R.G. Refinement of AOAC Official Method 2005.06 liquid chromatography-fluorescence detection method to improve performance characteristics for the determination of paralytic shellfish toxins in king and queen scallops. J. AOAC Int. 2012, 95, 129-142. [CrossRef] [PubMed]

14. Turner, A.D.; Hatfield, R.G.; Rapkova-Dhanji, M.; Norton, D.M.; Algoet, M.; Lees, D.N. Single-laboratory validation of a refined AOAC HPLC method 2005.06 for oysters, cockles, and clams in U.K. shellfish. J. AOAC Int. 2010, 93, 1482-1493. [PubMed]

15. Ben-Gigirey, B.; Rodriguez-Velasco, M.L.; Gago-Martinez, A. Extension of the validation of AOAC Official Method 2005.06 for dc-GTX2,3: Interlaboratory study. J. AOAC Int. 2012, 95, 111-121. [CrossRef] [PubMed] 
16. DeGrasse, S.L.; van de Riet, J.; Hatfield, R.; Turner, A. Pre- versus pos-tcolumn oxidation liquid chromatography fluorescence detection of paralytic shellfish toxins. Toxicon 2010, 57, 619-624. [CrossRef] [PubMed]

17. Vale, C.; Alfonso, A.; Vieytes, M.R.; Romaris, X.M.; Arevalo, F.; Botana, A.M.; Botana, L.M. In vitro and in vivo evaluation of paralytic shellfish poisoning toxin potency and the influence of the $\mathrm{pH}$ of extraction. Anal. Chem. 2008, 80, 1770-1176. [CrossRef] [PubMed]

18. Alonso, E.; Alfonso, A.; Vieytes, M.R.; Botana, L.M. Evaluation of toxicity equivalent factors of paralytic shellfish poisoning toxins in seven human sodium channels types by an automated high throughput electrophysiology system. Arch. Toxicol. 2015, 90, 1-10. [CrossRef] [PubMed]

19. Perez, S.; Vale, C.; Botana, A.M.; Alonso, E.; Vieytes, M.R.; Botana, L.M. Determination of Toxicity Equivalent Factors for Paralytic Shellfish Toxins by Electrophysiological Measurements in Cultured Neurons. Chem. Res. Toxicol. 2011, 24, 1153-1157. [CrossRef] [PubMed]

20. Oshima, Y. Postcolumn derivatization liquid chromatographic method for paralytic shellfish toxins. J. AOAC Int. 1995, 78, 528-532.

21. Rourke, W.A.; Murphy, C.J.; Pitcher, G.; Van de Riet, J.M.; Burns, B.G.; Thomas, K.M.; Quilliam, M.A. Rapid postcolumn methodology for determination of paralytic shellfish toxins in shellfish tissue. J. AOAC Int. 2008, 91, 589-597. [PubMed]

22. Van de Riet, J.M.; Gibbs, R.S.; Chou, F.W.; Muggah, P.M.; Rourke, W.A.; Burns, G.; Thomas, K.M.; Quilliam, M.A. Liquid chromatographic post-column oxidation method for analysis of paralytic shellfish toxins in mussels, clams, scallops, and oysters: Single-laboratory validation. J. AOAC Int. 2009, 92, 1690-1704. [PubMed]

23. Van de Riet, J.M.; Gibbs, R.S.; Muggah, P.M.; Rourke, W.A.; MacNeil, J.D.; Quilliam, M.A. Liquid chromatography post-column oxidation (PCOX) method for the determination of paralytic shellfish toxins in mussels, clams, oysters, and scallops: Collaborative study. J. AOAC Int. 2010, 94, 1154-1176.

24. AOAC. Official method 2011.02 Determination of paralytic shellfish poisoning toxins in mussels, clams, oysters and Scallops. In Post-Column Oxidation Method (PCOX); First Action 2011; AOAC International: Gaithersburg, MD, USA, 2011.

25. Biré, R.; Krys, S.; Frémy, J.M.; Dragacci, S. Improved Solid-Phase Extraction Procedure in the Analysis of Paralytic Shellfish Poisoning Toxins by Liquid Chromatography with Fluorescence Detection. J. Agric. Food. Chem. 2003, 51, 6386-6390. [CrossRef] [PubMed]

26. Boundy, M.J.; Selwood, A.I.; Harwood, D.T.; McNabb, P.S.; Turner, A.D. Development of a sensitive and selective liquid chromatography-mass spectrometry method for high throughput analysis of paralytic shellfish toxins using graphitised carbon solid phase extraction. J. Chromatogr. A 2015, 1387, 1-12. [CrossRef] [PubMed]

27. Vlamis, A.; Katikou, P.; Rodriguez, I.; Rey, V.; Alfonso, A.; Papazachariou, A.; Zacharaki, T.; Botana, A.M.; Botana, L.M. First Detection of Tetrodotoxin in Greek Shellfish by UPLC-MS/MS Potentially Linked to the Presence of the Dinoflagellate Prorocentrum. minimum. Toxins 2015, 7, 1779-1807. [CrossRef] [PubMed]

28. Turner, A.D.; Powell, A.; Schofield, A.; Lees, D.N.; Baker-Austin, C. Detection of the pufferfish toxin tetrodotoxin in European bivalves, England, 2013 to 2014. Euro Surveill. 2015, 20, 1-33. [CrossRef]

29. Bane, V.; Lehane, M.; Dikshit, M.; O’Riordan, A.; Furey, A. Tetrodotoxin: Chemistry, toxicity, source, distribution and detection. Toxins 2014, 6, 693-755. [CrossRef] [PubMed]

30. Saoudi, M.; Rabeh, F.B.; Jammoussi, K.; Abdelmouleh, A.; Belbahri, L.; El Feki, A. Biochemical and physiological responses in Wistar rat after administration of puffer fish (Lagocephalus lagocephalus) flesh. J. Food Agric. Environ. 2007, 5, 107-111.

31. Noguchi, T.; Ebesu, J.S.M. Puffer poisoning: Epidemiology and treatment. Toxin Rev. 2001, 20, 1-10. [CrossRef]

32. Bentur, Y.; Ashkar, J.; Lurie, Y.; Levy, Y.; Azzam, Z.S.; Litmanovich, M.; Golik, M.; Gurevych, B.; Golani, D.; Eisenman, A. Lessepsian migration and tetrodotoxin poisoning due to Lagocephalus sceleratus in the eastern Mediterranean. Toxicon 2008, 52, 964-968. [CrossRef] [PubMed]

33. Rodriguez, P.; Alfonso, A.; Vale, C.; Alfonso, C.; Vale, P.; Tellez, A.; Botana, L.M. First toxicity report of tetrodotoxin and 5, 6, 11-trideoxyTTX in the trumpet shell Charonia lampas lampas in Europe. Anal. Chem. 2008, 80, 5622-5629. [CrossRef] [PubMed]

34. Shiu, Y.C.; Lu, Y.H.; Tsai, Y.H.; Chen, S.K.; Hwang, D.F. Occurrence of tetrodotoxin in the causative gastropod Polinices didyma and another gastropod Natica lineata collected from western Taiwan. J. Food Drug Anal. 2003, 11, 159-163.

35. Yasumoto, T.; Tooru, M. Fluorometric determination of tetrodotoxin by high performance liquid chromatography. Agric. Biol. Chem. 1985, 49, 3077-3080. 
36. Wingerd, J.S.; Vetter, I.; Lewis, R.J. Voltage-Gated Sodium Channels as Therapeutic Targets. In Therapeutic Targets: Modulation, Inhibition, and Activation; Botana, L.M., Loza, M., Eds.; Wiley \& Sons: Hoboken, NJ, USA, 2012; pp. 63-122.

37. Kawabata, T. Assay method for tetrodotoxin. J. Food Hyg. Soc. Jpn. 1978, 2, 232-240.

38. Gessner, B.D.; McLaughlin, J.B. Epidemiologic Impact of Toxic Episodes: Neurotoxic Toxins. In Seafood and Freshwater Toxins: Pharmacology, Physiology, and Detection; Botana, L.M., Ed.; CRC Press Taylor \& Francis Group: Boca Raton, FL, USA, 2008; pp. 77-103.

39. Cohen, N.J.; Deeds, J.R.; Wong, E.S.; Hanner, R.H.; Yancy, H.F.; White, K.D.; Thompson, T.M.; Wahl, M.; Pham, T.D.; Guichard, F.M. Public health response to puffer fish (tetrodotoxin) poisoning from mislabeled product. J. Food Prot. 2009, 72, 810-817. [PubMed]

40. Scientific, T. Method Development Guide for Hypercarb Columns; Thermo Scientific: Runcorn, UK, 2007.

41. AOAC. Official method 959.08. Paralytic shellfish poison. Biological method. Final action. In AOAC Official Methods for Analysis; AOAC: Gaithersburg, MD, USA, 2005; pp. 79-80.

42. Botana, L.M.; Vieytes, M.R.; Alfonso, A.; Louzao, M.C. Phycotoxins. Paralytic Shellfish Poisoning. Diarrhetic Shellfish Poisoning. In Handbook of Food Analysis; Nollet, L., Ed.; Marcel Dekker Inc.: London, UK, 1996; pp. 1147-1170.

43. Hummert, C.; Ritscher, M.; Reinhardt, R.; Luckas, B. Analysis of the characteristic PSP profiles of Pyrodinium bahamense and several strains of Alexandrium by HPLC based on ion-pair chromatographic separation, post-column oxidation, and fluorescence detection. Chromatographia 1997, 45, 312-316. [CrossRef]

44. Luckas, B. Chemical Analysis of PSP Toxins. In Seafood and Freshwater Toxins: Pharmacology, Physiology and Detection, 2nd ed.; Botana, L.M., Ed.; CRC Press Taylor \& Francis Group: Boca Raton, FL, USA, 2000; pp. 173-186.

45. Ben-Gigirey, B.; Rodriguez-Velasco, M.L.; Otero, A.; Vieites, J.M.; Cabado, A.G. A comparative study for PSP toxins quantification by using MBA and HPLC official methods in shellfish. Toxicon 2012, 60, 864-873. [CrossRef] [PubMed]

46. Rey, V.; Alfonso, A.; Botana, L.M.; Botana, A.M. Influence of Different Shellfish Matrices on the Separation of PSP Toxins Using a Postcolumn Oxidation Liquid Chromatography Method. Toxins 2015, 7, 1324-1340. [CrossRef] [PubMed]

47. IUPAC. Guidelines for Collaborative Study of Procedure to Validate Characteristics of a Method of Analysis. J. AOAC Int. 1989, 72, 694-704.

48. Peters, F.T.; Drummer, O.H.; Musshoff, F. Validation of new methods. Forensic Sci. Int. 2007, 165, $216-224$. [CrossRef] [PubMed]

49. Lindner, W.; Wainer, I.W. Requirements for initial assay validation and publication in J. Chromatography B. J. Chromatogr. B 1998, 707, 1-2.

50. Alder, L.; Holland, P.T.; Lantos, J.; Lee, M.; McNeil, J.D.; O’Rangers, J.; Van Zoonen, P.; Ambrus, A. Guidelines for Single Laboratory Validation of Analytical Methods for Trace Level Concentrations of Organic Chemical. In Principles and Practices of Method Validation; Fajgelj, A.A.A., Ed.; The Royal Society of Chemistry: Cambridge, UK, 2000; p. 18.

51. Hwang, D.F.; Cheng, C.A.; Tsai, H.T.; Shih, D.Y.C.; Ko, H.C.; Yang, R.Z.; Jeng, S.S. Identification of Tetrodotoxin and Paralytic Shellfish Toxins in Marine Gastropods Implicated in Food Poisoning. Fish. Sci. 1995, 61, 675-679.

52. Nagashima, Y.; Maruyama, J.; Noguchi, T.; Hashimoto, K. Analysis of paralytic shellfish poison and tetrodotoxin (in shellfish and fish) by ion-pairing high performance liquid chromatography. Bull. Jpn. Soc. Sci. Fish. 1987, 53, 819-823. [CrossRef]

53. Martin-Smith, M.; Rudd, D.R. The importance of proper validation of the analytical methods employed in the quality control pharmaceuticals. Acta Pharm. Jugosl. 1990, 40, 7-19.

54. Camacho Sanchez, M.A.; Torres Suarez, A.I.; Gil Alegre, M.E.; Obregon Sanchez, M.M.; Ruz Palomar, V. Validation protocol of analytical methods for finished pharmaceutical products. STP Pharma Prat. 1993, 3, 197-202. 